УДК 378.1

МРНТИ 14.35.05

DOI 10.37238/1680-0761.2021.83(3).1

\author{
${ }^{1}$ Болотова М.И.*, ${ }^{2}$ Воробьев Д.О. \\ ${ }^{1,2}$ Оренбургский государственный медицинский государственный университет, \\ г. Оренбург, Россия \\ *Автор-корреспондент: orlova-str@mail.ru \\ E-mail: orlova-str@mail.ru
}

\title{
ВОСПИТАНИЕ НРАВСТВЕННОЙ УСТОЙЧИВОСТИ У СТУДЕНТОВ-ИНОСТРАНЦЕВ В ВУЗЕ
}

\begin{abstract}
Аннотация: Высшее образование в России находится на стадии глобальной трансформачии. Благодаря своему качеству оно вызывает интерес молодежи из стран ближнего и дальнего зарубежья. Количество иностранных студентов с каждым годом растет. Возрастает необходимость воспитательной работы с иностранныли студентами, усиление духовнонравственного компонента в условиях обострения межнациональных и межгосударственных конфликтов. Воспитание нравственной устойчивости предполагает формирование, с одной стороны, устойчивости личности, с другой - ее гибкости. Такая постановка вопроса связана $c$ тем, что в новых сочио-культурных условиях студент-иностранеи может жить и успешно обучаться лишь обладая высокой психологической гибкостью, способностью адаптироваться как $к$ новым экономическим, сочиальным и культурным реалиям, так и к ближайшему студенческому окружению и профессиональной иноязычной среде. Иначе в новой соииокультурной среде человек ответит дезадаптацией.
\end{abstract}

Ключевые слова: высшее медицинкое образование, иностранные студенты, нравственная устойчивость, учебно-воспитательная деятельность вуза, нравственные основания.

\section{Введение}

Современное высшее образование в России является активно меняющейся и развивающейся средой, примером этого являются постоянные изменения в федеральном государственном образовательном стандарте. Эти изменения жизненно необходимы, так как постиндустриальный тип развития общества, построенный на приоритете знаний и информации, требуют постоянного поиска качественного и мобильного обучения. Образование становится важнейшей сферой конкуренции среди государств, поэтому конкуренция за развитый рынок образовательных услуг усиливается. Страны, которые не могут по тем или иным причинам обучать свою молодежь, ищут государства, способные обеспечить достойный уровень квалификации специалиста. Интернациональное образование постоянно расширяется, становится обыденным наличие в университетах не только иностранцев-одиночек, но и наличие целых факультетов, на которых обучаются студенты из разных стран.

В нормативных документах модернизации российского образования утверждалась необходимость последовательного и качественного развития отечественного образования, опору на духовно-нравственный компонент без которого невозможно ни обучающий компонент, ни воспитывающий [1]. В «Стратегии развития воспитания в Российской Федерации на период до 2025 года» отмечается, что современное образование направлено не только на подготовку всесторонне развитого специалиста, квалифицированного работника, но и на формирование специалиста с высоким чувством ответственности, развитыми нравственными качествами [2]. Особенно важно, чтобы личность сочетала в себе высоконравственные принципы, основанные на традиционных 

реализовать свой человеческий и личностный потенциал.

Утверждение приоритета культуры призвано обеспечить более высокое качество общества, его способность к гражданскому единству, к определению и достижению общих целей развития. Главным условием их реализации является формирование нравственной, ответственной, самостоятельно мыслящей, творческой личности [3]. Кроме того в соответствии с Федеральным законом «Об образовании в Российской Федерации» «содержание образования должно содействовать взаимопониманию и сотрудничеству между людьми, народами независимо от расовой, национальной, этнической, религиозной и социальной принадлежности, учитывать разнообразие мировоззренческих подходов» [4].

\section{Материаль и методы исследования}

Результат образовательной деятельности российской школы фиксируется в портрете выпускника - «осознающего себя личностью, способной принимать самостоятельные решения и нести за них ответственность перед самим собой и другими людьми» [5]. Цель современного отечественного высшего образования и одна из приоритетных задач общества и государства определяется федеральным стандартом как «воспитание, социально-педагогическая поддержка становления им развития, высоконравственного, ответственного, творческого, инициативного, компетентного гражданина» [6]. Так, современный выпускник в результате освоения учебной программы по специальности «31.05.01 Лечебное дело» должен обладать следующими универсальными компетенциями: способен осуществлять критический анализ проблемных ситуаций на основе системного подхода, вырабатывать стратегию действий; способен анализировать и учитывать разнообразие культур в процессе межкультурного взаимодействия; а также такой общепрофессиональной компетенцией способен реализовывать моральные и правовые нормы, этические и деонтологические принципы в профессиональной деятельности [7].

Для иностранных студентов процесс непрерывного образования начинается с подготовительного факультета, который призван дать студентам-иностранцам необходимый уровень владения русским языком. Являясь обязательной составной частью обучения иностранных граждан в системе российского высшего образования, именно русский язык должен подготовить иностранцев по ряду предметов и адаптировать их к требованиям вуза.

На этом этапе в числе прочего важно, чтобы воспитательные задачи были направлены на знакомство с новой для иностранцев культурой и приобщение к ней. В течение первого года пребывания в России иностранные учащиеся впервые осознают её роль и место в мировой истории и культуре. Они впервые утверждаются в мысли о важности общечеловеческих ценностей вне зависимости от национальных, культурных и религиозных традиций. Немаловажное значение имеют национально-психологические особенности личности, без учёта которых нельзя ожидать успешных результатов работы с иностранными обучающимися. И это только начало приобщения иностранных студентов к общечеловеческой культуре, без чего невозможно формирование творческой личности, образованного человека, то есть человека, который, приобретя определённый социальный опыт, приобретает также и «способности пользоваться им (усвоенным опытом) в своей жизнедеятельности» $[8,9]$.

Анализ актуальности процесса формирования нравственной устойчивости у иностранных студентов, как педагогической проблемы, необходимо рассматривать изначально через педагогический анализ понятия «нравственная устойчивость».

Нравственная устойчивость состоит из двух понятий «нравственность» и «устойчивость». Толковый словарь понятий В.И. Левина определяет нравственность как один из самых важных и существенных факторов общественной жизни, общественного развития и исторического прогресса. Она заключается в добровольном самодеятельном согласовании чувств, стремлений и действий членов общества с чувствами, стремлениями и действиями сограждан, их интересом и достоинством, с интересом и достоинством всего общества в целом [10]. В свою очередь, толковый словарь С. И. Ожегова трактует нравственность, как «внутренние, духовные качества, которыми руководствуется человек, этические нормы; правила поведения, определяемые этими качествами», а нравственным человеком является тот, кто обладает этими духовными качествами, и свободно руководствуется в своей жизни сформированными на их основе этическими нормамир [11]. 
Известный отечественный педагог-исследователь Я. С. Марьенко, трактует понятие нравственность, как «неотъемлемую часть личности, обеспечивающую добровольное соблюдение существующих норм, правил и принципов поведения» [12].

В работах таких известных российских педагогов, как С. К. Бондырева, Н. В. Борытко, Л.А. Григоровича, Т.А. Дронова и др., нравственность рассматривается как личностная черта, сочетающая в себе такие качества и атрибуты, как доброта, порядочность, дисциплинированность и коллективизм [13]. Поэтому мораль непосредственно связана с устойчивостью, которые в свою очередь изучаются двояко: внешне, что служит механизмом социального контроля над личностью, и саморегуляцией внутреннего сознания на основе саморефлексии.

Таким образом, в общественном сознании складывается такая позиция, что каждая личность обладает соответствующими нравственными механизмами, которые осуществляют контроль ее действий и поступков. В основе этих нравственных механизмов как раз и должна лежать нравственная устойчивость. Ядром нравственной устойчивости должны выступать личные нравственные качества, которые являются продуктом рефлексии и самопознания. Каждый поступок или действие несет за собой нравственный выбор, и поэтому так важно развивать нравственные качества личности.

В свою очередь устойчивость уже давно является одним из ведущих понятий в гуманитарных науках. Психолого-педагогический аспект понятия впервые в отечественной науке был открыт Л.И. Божович, которая полагала, что под устойчивостью следует понимать особую иерархическую систему мотивов, которые возникают в течении жизни человека и в результате целенаправленной воспитательной деятельности. Постепенно образуются доминирующие мотивы, которые подчиняют себе остальные [14]. В Большом психологическом словаре под редакцией Б. Мещерякова и В. Зинченко, устойчивость понимается, как способность человека регулировать свое поведение исходя из принятых и усвоенных им нравственных норм и принципов. В ее основе лежат такие качества, как сознательность, гуманность, достоинство, чувство долга и личной ответственности, верность нравственным нормам (законам), инициативность в их соблюдении [15]. В. Э. Чудновский в своих исследованиях приходит к выводу о том, что устойчивость - качество личности, определяющее ее внутреннюю и внешнюю стабильность, в том числе и нравственную. Она заключается в сопротивлении негативным эффектам и явлениям извне [16]. Его точку зрения поддерживает Е.В. Головко, который отмечает, что устойчивость личности заключается в умении использовать морально-нравственные нормы так, чтобы они давали минимальное количество негативных действии в социальном взаимодействии [17]. И.Ф. Харламов отмечает, что именно опыт и знания становятся почвой, которая обеспечивает устойчивость личности [18]. Такой же позиции придерживается и О.В. Михайлова, считая опыт непосредственного соприкосновения личности и общества одним из важнейших факторов формирования нравственной позиции, которая очень сильно зависит от культуры [19]. В.А. Данилова в диссертационной работе «Формирование нравственной устойчивости у студентов технического вуза» (2007г.) также подтверждает фундаментальное значение нравственной устойчивости для специалиста [20].

В своих диссертационных исследованиях (Т.В. Кононенко «Воспитание нравственной устойчивости у студентов педагогических вузов» (2004 г.); В.Ф. Маленчук «Формирование нравственной устойчивости осужденных в процессе образовательной деятельности» (2010 г.); С.Н. Тихомиров «Формирование основ профессионально-нравственной устойчивости у курсантов и слушателей образовательных учреждений МВД России» (1999г.)) приходят к выводу о том, нравственная устойчивость является сложным комплексным феноменом, сочетающим в себе сущностные качества нравственной воспитанности, нравственных принципов жизни, противостоящие деструктивным воздействиям среды [21, 22, 23].

В результате проведенного нами анализа понятийного поля педагогической проблемы «воспитание нравственной устойчивости», мы пришли к выводу о том, что нравственная устойчивость это особое качество личности, формирующееся в практическом опыте реализации морально-нравственных норм в обществе, и основанное на закреплении и сохранении позитивных образцов деятельности, а также противодействию деструктивным аспектам жизни.

Результаты исследования

В ходе эксперимента мы провели в 2018-2019 гг. диагностическое исследование с целью оценки сформированности нравственных основ у иностранных студентов (индийские студенты, 
обучающиеся в Оренбургском Государственном Медицинском Университете, возраст 17 - 18 лет). В 2020-2021 гг. был проведен констатирующий эксперимент, мы обратились к стандартизированному опроснику моральных оснований «Moral foundations» (MFQ-30; Дж. Грехем, Дж. Хайдт, Б. Носек) на английском языке. Исследование проводилось в качестве педагогического онлайн анкетирования. Нами было опрошено 143 респондента (индийские студенты, обучающиеся в Оренбургском Государственном Медицинском Университете, возраст 17 -18 лет).

Данная диагностическая методика была направлена на уточнение значимости базовых жизненных ценностей респондентов, которые обуславливают моральный/нравственный профиль личности, с целью дальнейшего повышения воспитательного потенциала учебной дисциплины «История». Кроме того, опросник базируется на принципе культурной вариативности, что позволяет добиться валидности результатов исследования среди иностранных студентов.

При обработке получаемых ответов вычислялся средний балл по 5 шкалам: забота/нанесение вреда, честность/жульничество, преданность/склонность к предательству, власть/противодействие власти, чистота (святость)/деградация. Количественный анализ входной диагностики показал следующий результат: $29 \%$ студентов - низкий результат, $38 \%$ - средний результат.

На основе полученных данных были сделаны выводы о необходимости усиления педагогического воздействия на личность студента, усиление воспитательного компонента учебной деятельности (рабочая программа дисциплины «История», «Курс лекций по предмету История», «Хрестоматия по истории»). В течение учебного года проводились открытые лекции и семинары, диспуты, иностранные студенты активно привлекались к внеаудиторной учебной деятельности (учебные экскурсии в музеи и выставки г. Оренбурга). Кроме того, студенты привлекались к научной работе, рассматривая сложные исторические проблемы и вопросы индийской и российской истории.

Количественная характеристика результатов в 2019-2020 гг. показала, что процент высоких баллов по выше перечисленным шкалам значительно увеличился.

Так, высокие баллы по шкале «Забота/Нанесение вреда» говорили о том, что среди студентов преобладали ценности любви к ближнему, заботы об окружающих людях и окружающей среде, развитую способность к эмпатии и межличностному взаимодействию. Для человека с высоким уровнем «заботы» не существует чужих проблем. Его сопровождает желание делать мир лучше.

Высокие баллы по шкале «Честность/жульничество» указывали на преобладание ценностей честности и справедливости в отношениях с окружающими. Это утверждение подтверждается практически, на занятиях иностранного факультета студенты крайне щепетильно относятся к оценке своих действий, требуя прямого и честного ответа, не испытывая страха перед рефлексией и позитивными, конструктивными изменениями в своей личности.

Высокие баллы по шкале «Преданность/склонность к предательству» показывали склонность человека к преданности той социальной группе, с которой он себя идентифицирует. Все окружающие для такого человека разделяются на «своих» и «чужих». «Своих» человека с высокой ценностью преданности готов защищать ценой собственного комфорта. Жизнь же «чужих» мало его волнует. Это, прежде всего, связано с тем, что по историческим меркам в середине XX века Индия, как государство обрело независимость и прошло труднейший путь своего развития, связанный с различными внутренними конфликтами на политической, религиозной и культурной почве. Также повлияла варно-кастовая система, которая была доминантой тысячи лет и лишь недавно перестала быть таковой. Кроме того, высокие баллы данной шкалы фиксировали склонность личности к патриотизму. Поэтому крайне важно учитывать данные показатели при работе с иностранными студентами, формируя позитивный образ своей страны и индийской нации как целого.

Средние показатели по шкале «Власть/противодействие власти» характеризуют противоречия, которые характерны для современного индийского общества: кастовые барьеры, социальные проблемы, демография, экология, все это очень сильно беспокоит молодое индийское студенчество. Поэтому авторитет, регалии воспринимаются молодыми людьми не так однозначно. Они более холодно относятся к традициям, правилам национального поведения, подчинения. Это также связано с тем, что молодые люди, находясь в цифровом пространстве, видят успехи своих сверстников за рубежом, их возможности и понимают, что в своей стране по социальной лестнице они высоко подняться не смогут без хорошего образования. Тем не менее, у молодежи негативного отношения к власти, обычаям и традициям не сложилось. И поэтому такой результат говорит нам о 
крайней необходимости проведения воспитательной работы со студентами, чтобы закреплять нравственные парадигмы поведения.

Средние значения по шкале «Святость/деградация» показывает нам нарастающий кризис духовных ценностей индийского общества. Постепенно вместо религиозных ценностей, идеалов моральной и физической чистоты начинают появляться идеалы общества потребления, организованных на основе принципа индивидуального потребления. У современной молодежи формируется соответствующая система ценностей и установок, часто не базирующаяся на принципах нравственности и гуманизма, что актуализирует необходимость воспитания нравственной устойчивости личности.

\section{Заключение}

Таким образом, актуальность исследования проблемы воспитания нравственной устойчивости у иностранных студентов крайне высока. В результате глобализации и обострения международной обстановки нашей стране как никогда нужны люди, которые будут позитивно относиться к своей стране и поддерживать ее. Поэтому так важно акцентировать и реализовывать воспитательный потенциал высшего образования, который сформирует основу в виде крепкого и устойчивого нравственного субстрата в личности обучающегося.

\section{ЛИТЕРАТУРА}

[1] Концепиия модернизаџии российского образования на период до 2010 года. [Электронньй pecypc]. - Режим достуnа: https://docs.cntd.ru/document/901816019

[2] Стратегия развития воспитания в Российской Федераџии на период до 2025 года. [Электронный ресурс]. - Режим доступа: http://static.government.ru/media/files/ f5Z8H9tgUK5Y9qtJOtEFnyHlBitwN4gB.pdf

[3] Указ Президента Российской Федеращии от 24.12.2014 2. № 808. Об утверждении Основ государственной культурной политики. [Электронный ресурс]. - Режим доступа: http://www.kremlin.ru/acts/bank/39208

[4] Федеральный закон от 29.12.2012 N 273-Ф3 (ред. от 24.04.2020) "Об образовании 6 Российской Федераџии". [Электронный ресурс]. - Режим доступа: http://www.consultant.ru/ document/cons_doc_LAW_140174/b819c620a8c698de35861ad4c9d9696ee0c3ee7al

[5] Данилюк, А.Я. Концепџия духовно-нравственного развития и воспитания личности гражданина России [Электронный ресурс] / А.Я. Данилюк, А.М. Кондаков, В.А. Тишков //. - М.: Просвещение, 2009. - $24 \quad$ c. Режим достуnа: https://schsv760.mskobr.ru/ attach_files/upload_users_files/5dc90b2cd145a.pdf

[6] Федеральные государственные образовательные стандарты общего образования. [Электронный ресурс]. - Режим доступа: https://fgos.ru/

[7] Приказ № 988 «Об утверждении федерального государственного образовательного стандарта высшего образования - специалитет по спещиальности 31.05 .01 Лечебное дело». [Электронный ресурс]. - Режим достуnа: http://publication.pravo.gov.ru/ Document/View/ 0001202008270013

[8] Сочиально-экономические и технические системы: исследование, проектирование, оптимизация. Изд-во: Набережночелнинский институт (филиал) Казанского (Приволжского) федерального университета. № 5 (72), 2016 (спец.выпуск). Режим доступа: https://kpfu.ru/portal/docs/F860630145/_5_72_.2016.pdf

[9] Филимонова Н.Ю. Проблемы воспитания иностранных студентов как проблемь саморазвития личности / Н. Ю.Филимонова, Е. А. Годенко // Научный Вестник МГТУ ГА, сер. Международная деятельность вузов. МГТУ ГА.-№ 94(12). - 2005, c.51- 60.

[10] Левин В.И. Философия, логика и методология науки [Электронный ресурс] / В. И. Левин // М-во образования и науки Российской Федераиии, Гос. образовательное учреждение выси. проф. образования "Пензенская гос. технологическая акад.". - Пенза: ПГТА, 2010. - 66 с. Режим доступа: http://philosophy.niv.ru/doc/dictionary/philosophy/index-205.htm\#205
[11] Толковый
словарь
Ожегова.
Режим доступа:
https://slovarozhegova.ru/ word.php? wordid $=17288$ 
[12] Марьенко И.С. Нравственное становление личности школьника / И. С. Марьенко. - М.: Педагогика, 1985. - 103 c

[13] Приказ № 988 «Об утверждении федерального государственного образовательного стандарта высшего образования - спещиалитет по специальности 31.05 .01 Лечебное дело». [Электронный ресурс]. - Режим доступа: http://publication.pravo.gov.ru/ Document/View/0001202008270013

[14] Божович Л.И. Личность и ее формирование в детском возрасте. (Психологическое исследование.) [Электронный ресурс] / Л.И. Божович - М., «Просвещение», 1968. 464 с. (Акад. пед. наук СССР). Режим достуnа: https://sdo.mgaps.ru/books/K4/M5/file/4.pdf

[15] Мещеряков Б., Зинченко В. Большой психологический словарь. [Электронный ресурс]. Режим доступа: https://www.gumer.info/bibliotek_Buks/Psihol/dict/19.php

[16] Чудновский В.Э. Нравственная устойчивость личности: Психологические исследования / В. Э. Чудновский. - М.: Педагогика, 1981. - 208 с.

[17] Головко Е.В. Формирование нравственной устойчивости младмего икольника к отрицательным влияниям микросреды: автореферат дис. на соискание уч. степени канд. пед. наук: спеи. 13.00.01 / Е. В. Головко - Белгород. гос. ун-т. - Белгород, 2004. - 22 с.

[18] Харламов И.Ф. Педагогика: Учеб. пособие. - 4-е изд., перераб. и доп. / И.Ф. ХарламовМ.: Гардарики, 2003. - 519 c.

[19] Михайлова О. В. Формирование нравственной устойчивости у подростков в системе деятельности классного руководителя сельской школь: автореферат дис. на соискание уч. степени канд. пед. наук: спеи. 13.00.01 / О. В.Михайлова. - Чебоксары, 2004. - 22 с. Режим доступа: http://nauka-pedagogika.com/pedagogika-13-00-01/dissertaciya-formirovanie-nravstvennoy-ustoychivosti-upodrostkov-v-sisteme-deyatelnosti-klassnogo-rukovoditelya-selskoy-shkoly

[20] Данилова В.А. Формирование нравственной устойчивости у студентов технического вуза: автореферат дис. на соискание уч. степени канд. пед. наук: спец. 13.00.08 / В. А. Данилова Чебоксары, 2007. - 19 c.

[21] Кононенко Т.В. Воспитание нравственной устойчивости у студентов педагогических вузов: автореферат дис. на соискание уч. степени канд. пед. наук: спеи. 13.00.01 [Электронный ресурс] / T. В. Кононенко - Адыг. гос. ун-т. - Майкоп, 2004. - 17 с. Режим доступа: https://docplayer.com/218327291-Kononenko-tatyana-viktorovna-vospitanie-nravstvennoy-ustoychivosti-ustudentov-pedagogicheskih-vuzov.html

[22] Маленчук В.Ф. Формирование нравственной устойчивости осужденных в прочессе образовательной деятельности: автореферат дис. на соискание уч. степени канд. пед. наук: спеи. 13.00.01 / В. Ф.Маленчук - Тверь, 2010. - 26 с.

[23] Тихомиров С.Н. Формирование основ профессионально-нравственной устойчивости у курсантов и слушателей образовательных учреждений МВД России: диссертация на соискание уч. степени канд. пед. наук: спец. 13.00.01/ С. Н. Тихомиров - Москва, 1999. - 257 с.

\section{REFERENCES}

[1] Koncepciya modernizacii rossijskogo obrazovaniya na period do 2010 goda[The concept of modernization of Russian education for the period up to 2010.]. - Retrieved from: https://docs.cntd.ru/document/901816019 [in Russian].

[2] Strategiya razvitiya vospitaniya v Rossijskoj Federacii na period do 2025 goda. [ Strategy for the development of education in the Russian Federation for the period up to 2025] - Retrieved from: http://static.government.ru/media/files/f5Z8H9tgUK5Y9qtJOtEFny HlBitwN4gB.pdf [in Russian].

[3] Ukaz Prezidenta Rossijskoj Federacii ot 24.12.2014 g. № 808. Ob utverzhdenii Osnov gosudarstvennoj kul'turnoj politiki. [Decree of the President of the Russian Federation No. 808 of 24.12.2014. On the approval of the Fundamentals of the state Cultural policy] - Retrieved from: http://www. kremlin.ru/acts/bank/39208 [in Russian].

[4] Federal'nyj zakon ot 29.12.2012 N 273-FZ (red. ot 24.04.2020) "Ob obrazovanii v Rossijskoj Federacii". [Federal Law №. 273 - FZ of 29.12.2012 (as amended on 24.04.2020) "On Education in the Russian Federation"] (2020) - Retrieved from: http://www.consultant.ru/document/cons_doc_ LAW_140174/b819c620a8c698de35861ad4c9d9696ee0c3ee7al [in Russian]. 
[5] Danilyuk A.Ya., Kondakov A.M. \& V. A. Tishkov (2009) Koncepciya duhovno-nravstvennogo razvitiya $i$ vospitaniya lichnosti grazhdanina Rossii [The concept of spiritual and moral development and education of the personality of a citizen of Russia]. M.: Prosveshchenie, 24. Retrieved from: https://schsv760.mskobr.ru/attach_files/upload_users_files/5dc90b2cd145a.pdf [in Russian].

[6] Federal'nye gosudarstvennye obrazovatel'nye standarty obshchego obrazovaniya. [Federal State educational standards of general education] - Retrieved from: https://fgos.ru/ [in Russian].

[7] Prikaz № 988 «Ob utverzhdenii federal'nogo gosudarstvennogo obrazovatel'nogo standarta vysshego obrazovaniya - specialitet po special'nosti 31.05.01 Lechebnoe delo». [Decree №. 988 "On approval of the federal state educational standard of higher education-specialty in the specialty 31.05.01 Medical care".] - Retrieved from: http://publication.pravo.gov.ru/Document/View/0001202008270013 [in Russian].

[8] Social'no - ekonomicheskie i tekhnicheskie sistemy: issledovanie, proektirovanie, optimizaciya. [Socio - economic and technical systems: research, design, optimization.] Izd - vo: Naberezhnochelninskij institut (filial) Kazanskogo (Privolzhskogo) federal'nogo universiteta. Vol. 5 (72), 2016 (spec.vypusk). Retrieved from: https://kpfu.ru/portal/docs/F860630145/5_72_.2016.pdf [in Russian].

[9] Filimonova N. Yu., Godenko E. A. (2005) Problemy vospitaniya inostrannyh studentov kak problemy samorazvitiya lichnosti [Problems of education of foreign students as problems of personal selfdevelopment] Nauchnyj Vestnik MGTU GA, ser. Mezhdunarodnaya deyatel'nost' vuzov. MGTU GA.- Vol. 94(12), .51-60 [in Russian].

[10] Levin V. I. (2010) Filosofiya, logika i metodologiya nauki [Philosophy, logic and methodology of science]. M-vo obrazovaniya i nauki Rossijskoj Federacii, Gos. obrazovatel'noe uchrezhdenie vyssh. prof. obrazovaniya "Penzenskaya gos. tekhnologicheskaya akad.". - Penza: PGTA. Retrieved from: http://philosophy.niv.ru/doc/dictionary/philosophy/index-205.htm\#205 [in Russian].

[11] Tolkovyj slovar' Ozhegova. [Ozhegov's Explanatory Dictionary.] Retrieved from: https://slovarozhegova.ru/word.php?wordid=17288 [in Russian].

[12] Mar'enko I. S. (1985) Nravstvennoe stanovlenie lichnosti shkol'nika[he moral formation of a schoolboy's personality]. M.: Pedagogika. [in Russian].

[13] Borytko N. M. (2012) Eticheskaya koncepciya duhovno-nravstvennogo vospitaniya [The ethical concept of spiritual and moral education] Elektronnyj nauchno-obrazovatel'nyj zhurnal VGSPU «Grani poznaniya». Volgograd. Vol. 3 (17). Retrieved from: http://grani.vspu.ru/files/publics/ 1348482689.pdf [in Russian].

[14] Bozhovich L. I. (1968) Lichnost' i ee formirovanie v detskom vozraste. (Psihologicheskoe issledovanie.) [Personality and its formation in childhood. (Psychological research.)]. M., "Prosveshchenie» (Akad. ped. nauk SSSR). Retrieved from: https://sdo.mgaps.ru/books/K4/M5/file/4.pdf [in Russian].

[15] Meshcheryakov B., Zinchenko V. Bol'shoj psihologicheskij slovar'[Big psychological dictionary.]. Retrieved from: https://www.gumer.info/bibliotek_Buks/Psihol/dict/19.php [in Russian].

[16] Chudnovskij V. E. (1981) Nravstvennaya ustojchivost' lichnosti: Psihologicheskie issledovaniya [Moral stability of personality: Psychological research]. M.: Pedagogika [in Russian].

[17] Golovko E. V. (2004) Formirovanie nravstvennoj ustojchivosti mladshego shkol'nika $k$ otricatel'nym vliyaniyam mikrosredy [Formation of moral stability of a junior schoolboy to the negative influences of the microenvironment]. Extended abstract of candidate's thesis. Belgorod [in Russian].

[18] Harlamov I.F. (2003) Pedagogika: Ucheb. posobie. [Pedagogy: Textbook.]. 4-e izd., pererab. $i$ dop. M.: Gardariki [in Russian].

[19] Mihajlova O. V. (2004) Formirovanie nravstvennoj ustojchivosti u podrostkov v sisteme deyatel'nosti klassnogo rukovoditelya sel'skoj shkoly [Formation of moral stability in adolescents in the system of activity of the class teacher of a rural school]. Extended abstract of candidate's thesis. Cheboksary. Retrieved from: http://nauka-pedagogika.com/pedagogika-13-00-01/dissertaciya-formirovanienravstvennoy-ustoychivosti-u-podrostkov-v-sisteme-deyatelnosti-klassnogo-rukovoditelya-selskoy-shkoly [in Russian].

[20] Danilova V. A. (2007) Formirovanie nravstvennoj ustojchivosti u studentov tekhnicheskogo vuza [Formation of moral stability among students of a technical university]. Extended abstract of candidate's thesis. Cheboksary [in Russian].

[21] Kononenko T. V.(2004) Vospitanie nravstvennoj ustojchivosti u studentov pedagogicheskih vuzov [Education of moral stability among students of pedagogical universities]. Extended abstract of 

viktorovna-vospitanie-nravstvennoy-ustoychivosti-u-studentov-pedagogicheskih-vuzov.html [in Russian].

[22] Malenchuk V. F. (2010) Formirovanie nravstvennoj ustojchivosti osuzhdennyh v processe obrazovatel'noj deyatel'nosti [Formation of moral stability of convicts in the process of educational activity]. Extended abstract of candidate's thesis. Tver' [in Russian].

[23] Tihomirov S. N. (1997) Formirovanie osnov professional'no-nravstvennoj ustojchivosti $u$ kursantov $i$ slushatelej obrazovatel'nyh uchrezhdenij MVD Rossii [Formation of the foundations of professional and moral stability among cadets and students of educational institutions of the Ministry of Internal Affairs of Russia]. Candidate's thesis. Moskva. [in Russian].

\section{Bolotova Marina, Vorobiev Dmitry EDUCATION OF MORAL STABILITY IN FOREIGN STUDENTS AT THE UNIVERSITY}

Abstract: Higher education in Russia is at the stage of global transformation. Due to its quality, it arouses the interest of young people from near and far abroad. The number of international students is growing every year. There is an increasing need for educational work with foreign students, the strengthening of the spiritual and moral component in the conditions of aggravation of interethnic and interstate conflicts. The upbringing of moral stability presupposes the formation, on the one hand, of the stability of the personality, on the other, its flexibility. This formulation of the question is due to the fact that in the new socio-cultural conditions, a foreign student can live and study successfully only with high psychological flexibility, the ability to adapt both to new economic, social and cultural realities, and to the nearest student environment and professional foreign language environment. Otherwise, in a new socio-cultural environment, a person will respond with maladjustment.

Keywords: higher medical education, foreign students, moral stability, educational activities of the university, moral foundations.

\section{Болотова М.И., Воробьев Д.О. ЖОО-ДАҒЫ ШЕТЕЛ СТУДЕНТТЕРІНІН АДАМГЕРШІЛІК ТҰРАҚТЫЛЫҒЫН ТӘРБИЕЛЕУ}

Аңдатпа. Ресейдегі жоғары білім жаһандық трансформация кезеңінде. Оның сапасының арқасында ол жақын және алыс шет елдерден келген жастардың қызығушылығын тудырады. Жыл сайын шетелдік студенттер саны артып келеді. Шетелдік студенттермен тәрбие жұмысының қажеттілігі, ұлтаралық және мемлекетаралық қақтығыстардың шиеленісуі жағдайында руханиадамгершілік компонентті күшейту артып келеді. Адамгершілік тұрақтылықты тәрбиелеу бір жағынан тұлғаның тұрақтылығын, екінші жағынан оның икемділігін қалыптастыруды қамтиды. Сұрақтың бұл тұжырымы жаңа әлеуметтік-мәдени жағдайларда шетелдік студент жоғары психологиялық икемділікпен, жаңа экономикалық, әлеуметтік және мәдени шындыққа, сонымен қатар жақын студенттік ортаға және кәсіби шет тілдік ортаға бейімделу қабілетімен өмір сүріп, сәтті оқи алатындығымен байланысты. Әйтпесе, жаңа әлеуметтік-мәдени ортада адам дұрыс емес бейімделумен жауап береді.

Кілт сөздер: жоғары медициналық білім, шетелдік студенттер, адамгершілік тұрақтылық, университеттің оқу-тәрбие қызметі, адамгершілік негіздері. 